\title{
Research on Influencing Factors of Consumers' Willingness to Purchase Fresh E-commerce Products Based on UTAUT Model
}

\author{
Xu Yujin ${ }^{1,}$, Gao Wei ${ }^{1, b,}$, Yang Pei ${ }^{1, c}$ \\ ${ }^{1}$ School of Business, Sichuan Agricultural University, Chengdu 611830, China \\ acoastxyj@qq.com, ${ }^{b} 24921403 @ q q . c o m,{ }^{c}$ cactuspei@qq.com
}

Keywords: fresh e-commerce products; UTAUT; purchase intention; perceived risk

\begin{abstract}
In the transactions of fresh e-commerce products, consumers' purchase intention also occupies an important position. Therefore, this study is based on the Unified Theory of Acceptance and Use of Technology, combines the actual situation to construct the research model of the factors that influence the willingness of the consumers on buying fresh e-commerce products and designs a reasonable and accurate questionnaire for online investigation according to the existing literatures. Through empirical analysis, the results show that consumers' perception of risk significantly affect the willingness of consumers to buy fresh e-commerce products, the social influence does not significantly affect the willingness of consumers to buy fresh e-commerce products, and effort expectancy, impulsivity, performance expectancy of consumers have an effect on the intention to buy fresh e-commerce products. Finally, based on empirical results, this research gives several suggestions for fresh products e-commerce enterprises and government.
\end{abstract}

\section{Introduction}

With the rapid development of China's Internet technology, China's e-commerce industry has also developed in full swing. Only in the first half of 2017, the e-commerce transaction of China has reached to 13.35 trillion yuan, among which fresh e-commerce transactions only was 85.14 billion yuan, accounting for about $0.64 \%$ of the total turnover [1]. Such a sharp contrast shows that: the development of fresh e-commerce industry is still not sufficient, the fresh e-commerce enterprise's management practices and strategic planning is still a problem. According to the China Electronic Commerce Research Center monitoring data shows that in 2016, china has more than 4000 fresh e-commerce enterprises, but only 1 percent were profitable, $4 \%$ were flat, $88 \%$ were loss, and the remaining 7 percent is a huge loss [2]. Facing the extremely high loss rate of fresh e-commerce companies, some scholars have started to study the causes and seek solutions from the aspects of optimization, distribution mode, pricing, and business model of fresh e-commerce logistics 
distribution routes, but most of them are from the perspective of the seller to conduct research, few studies consider the issue from the perspective of the buyer.

Fresh products are primary products that can be sold without cooking and deep processing, and that are simply processed and kept fresh. The main fresh products are fruits, vegetables, aquatic products and meat [3]. According to the think-tank penguin online survey found that: The total consumption willingness of fresh e-commerce products has exceeded $70 \%$. However, due to the special nature of fresh products such as perishable, fragile, deteriorative, non-standard, high-loss, and high-packaging costs, the perceived risk of consumers will become higher and the perceived value will become lower. When the consumer's first purchase experience is lower than the consumer's expectation, the probability of repurchasing will decline, which may lead to a decrease in the profit of the fresh e-commerce company and even a loss. Then, in addition to the product attributes of the fresh product itself, the information richness of the site and other factors, what factors will affect the purchase of fresh e-commerce products from the buyer's perspective?

By sorting out existing papers, we can know that Wang Kexi, Yang Xiaopeng, Zhou T, Xiao Zhehui, Sun Yi and Chen Fanjiao have studied the influencing factors from the aspects of website experience, website information richness, seller service, product price, product brand, product quality and security and so on [4,5,6,7,8,9]. Dan Bin, Li Yimei, Zhang Yingyu, Chunhua XIE, Zhu Junhong and Slovice have conducted research on reference groups, consumer expectations and education level from the buyer's point of view [10,11,12,13,14,15]. Zhao Baoguo and Yan An have studied consumers' intention through the research and application of UTAUT [16,17].

From what have been discussed above, we know that it's rarely to see the research analysis model based UTAUT fresh providers online purchase intent factors on the current published literature. Most scholars use traditional way to expand their studies, therefore, the factors' accuracy and innovation have yet to be improved. Furthermore, most of the literature from the buyer's point of view is studied from the perspective of reference groups, consumer expectations, and educational level, but do not fully consider the impact of impulsivity, information availability, and perceived ease of use.

Based on the above considerations, this paper extracts the influencing factors from the buyer's point of view based on the integrated technology acceptance and use model (UTAUT), designs measurement tables according to previous literature, and collects data. After analyzing the reliability and validity of the data, it conducts factor analysis and correlation analysis to extract key factors, then through comprehensive evaluation to find out the influence of the factors, finally provide effective advice for the fresh e-commerce companies' marketing strategy and strategic planning, and for the government and other relevant departments to make fresh e-commerce industry development policies.

\section{Theory and Research Model}

\subsection{Theoretical Basis}

In recent years, as Internet users have grown explosively, with Internet technology and supporting services have gradually matured, in order to better connect the demands of the online platform and the audience of the online platform, thus promote the further development of e-commerce economy and technology, scholars in different fields at home and abroad have done some work on how to improve the original user technology acceptance model for further study. By inquiring the research results in related fields at home and abroad, we find that many scholars have adopted the Unified Theory of Acceptance and Use of Technology (UTAUT) when studying the influencing factors of consumers' purchase intention. The theory of UTAUT is proposed by Venkatesh which based on the TAM theory, 
the motivation model, the model of PC Utilization, the social cognitive theory, the innovation diffusion theory and other important theories [18]. UTAUT summarized four potential variables affecting users' willingness to use new technologies and their use behaviors: performance expectations, effort expectations, social influence, and contributing factors. The first three variables directly affect the consumers' willingness to use, and the last one directly affects their use behavior. At the same time, UTAUT also introduced four adjustable variables: gender, age, experience, and voluntariness. The relevant empirical results show that: UTAUT's interpretation of using behavior is up to $70 \%$, which is more effective than any model known in the past [19]., therefore, it is very effective to test user's willingness about the use of new technologies or systems and study the influence of the use intention on the behavior of use with UTAUT.

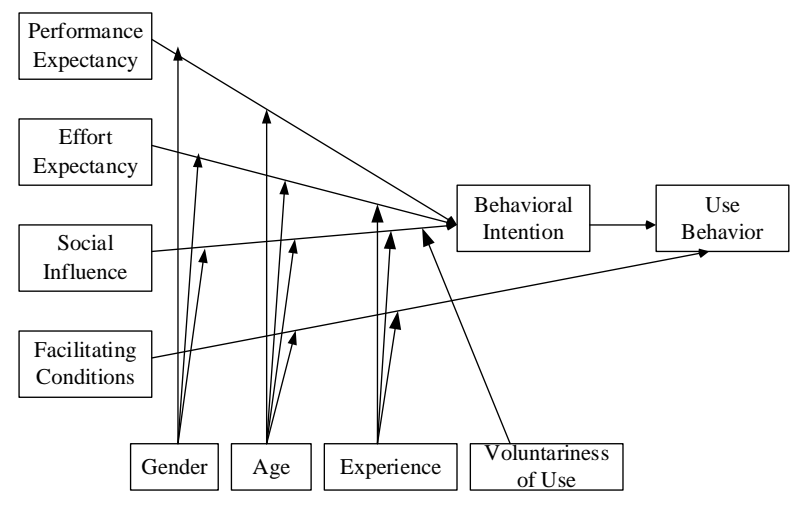

Fig. 1 UTAUT model (Vekatesh \& Davis, 2003)

\subsection{Research Model}

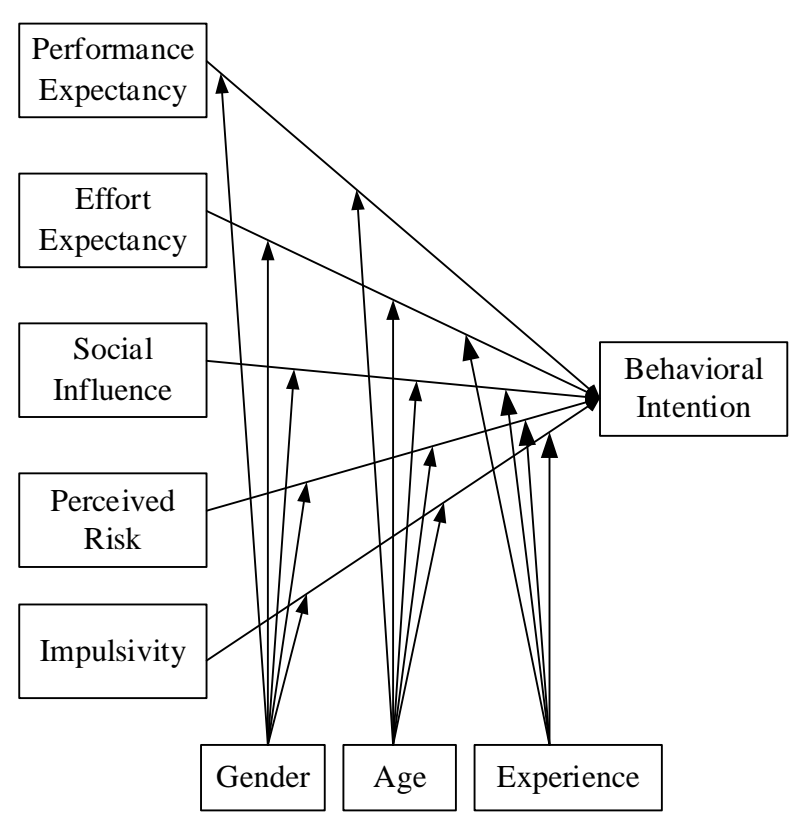

Fig. 2 Research model of influence factors of fresh e-commerce consumers' purchase intention

According to Venkatesh's research, when using UTAUT to evaluate technology adoption behavior, variables need to be selected according to the actual situation of the research object in order to maintain a good interpretation ability of the model. Based on the UTAUT theory, this paper retains three potential variables: performance expectations, effort expectations, and social impact in the 
original model. And based on the features of fresh products and fresh e-commerce platforms, this paper introduces two variables: perceived risk and impulsivity in the original model. Since the study was conducted on the premise of voluntary online shopping for fresh products by consumers, the voluntary of the UTAUT model does not affect the relationship between variables. Therefore, this article removes the voluntary variable in the original model. In addition, this article studies the factors that affect the willingness of fresh consumer e-commerce purchasers, but does not involve the influence of purchase intentions on purchase behavior. The research model of this paper is shown in Figure 2.

\section{Methodology}

\subsection{Questionnaire Design}

This study uses the questionnaire survey method to measure the variables in the model. The initial questionnaire of this study is based on the measurement scale in the previous literature. After the initial questionnaire was formed, combined with the opinions of the e-commerce research experts and the feedback of the pre-survey questions, the initial questionnaire was revised and perfected several times to ensure the validity of the questionnaire and the objectivity of the question. The questionnaire consists of two parts: The first part is the basic information of the respondents, including age, education, occupation, and experience. The second part is the main part of the questionnaire, where measures the five latent variables involved in the model. Using the Likert 5 scale to measure latent variables, the respondents chose the option of expressing their recognition of the problem from " strongly agree " to " strongly disagree " with five options. In order to ensure the validity of the questionnaire, all the questions in the main part of the questionnaire are from the existing literature.

\subsection{Sampling Design}

This study used the questionnaire online data collection platform, taking into account the geographical location of the shopping district and the impact of different groups of people on data collection, and the influence of convergence of questionnaires generated by different members of the same family. At the same time, this study selected Sichuan, Jiangsu, Zhejiang, Liaoning, Henan and other 13 provinces and Shanghai, Beijing, Tianjin, Chongqing 4 municipalities as research sites, therefore, this questionnaire ensures the scientific data, reliability and objectivity to a certain degree. In this questionnaire, a total of 239 questionnaires were distributed, 211 valid questionnaires were screened, the efficiency of the questionnaire was $88.28 \%$, and the overall situation was better.

\section{Data Analysis and Model Validation}

\subsection{Reliability and validity}

This paper uses the value of Cronbach's Alpha to measure the internal consistency of the questionnaire to analyze the reliability of the data by using SPSS22.0. Due to the latent variables of Cronbach's Alpha are all greater than 0.8 (see Table 1), the survey scale of this paper has high reliability.

In the exploratory factor analysis, this paper uses the KMO test and the Bartlett Test of Sphericity to determine whether it is suitable for factor analysis. From Table 2, it can be seen that the value of $\mathrm{KMO}$ is 0.924 and the value of Bartlett Test of Sphericity is 3022.962 with the corresponding 
probability is 0.000 . According to the commonly used KMO metrics given by Kaiser, we can know that with the value of 0.9 or higher is very suitable for factor analysis; 0.8 is suitable; 0.7 is general; 0.6 is not suitable; 0.5 or less is extremely unsuitable. Therefore, when the level of significance is 0.01 , the data described here is very suitable for factor analysis and the questionnaire has high validity.

Table 1 Mean, standard deviation and reliability of each variable table

\begin{tabular}{|c|c|c|c|c|}
\hline Variables & Items & Mean & Standard deviation & Cronbach's \\
\hline \multirow{5}{*}{$\mathrm{PE}$} & PE1 & 2.09 & 0.820 & \multirow{5}{*}{0.839} \\
\hline & PE2 & 1.83 & 0.882 & \\
\hline & PE3 & 1.90 & 0.864 & \\
\hline & PE4 & 1.67 & 0.886 & \\
\hline & PE5 & 2.32 & 0.981 & \\
\hline \multirow{5}{*}{$\mathrm{EE}$} & EE1 & 2.35 & 0.941 & \multirow{5}{*}{0.895} \\
\hline & EE2 & 2.27 & 0.881 & \\
\hline & EE3 & 2.15 & 0.843 & \\
\hline & EE4 & 2.50 & 0.992 & \\
\hline & EE5 & 2.21 & 0.842 & \\
\hline \multirow{2}{*}{ SI } & SI1 & 2.38 & 0.834 & \multirow{2}{*}{0.850} \\
\hline & $\mathrm{SI} 2$ & 2.30 & 0.806 & \\
\hline \multirow{5}{*}{ PR } & PR1 & 2.47 & 0.818 & \multirow{5}{*}{0.909} \\
\hline & PR2 & 2.55 & 0.906 & \\
\hline & PR3 & 2.45 & 0.817 & \\
\hline & PR4 & 2.52 & 0.853 & \\
\hline & PR5 & 2.31 & 0.773 & \\
\hline \multirow{4}{*}{ IM } & IM1 & 2.18 & 0.847 & \multirow{4}{*}{0.867} \\
\hline & IM2 & 2.14 & 0.819 & \\
\hline & IM3 & 2.09 & 0.811 & \\
\hline & IM4 & 2.33 & 0.824 & \\
\hline
\end{tabular}

Table 2 The value of KMO and Bartlett Test of Sphericity

\begin{tabular}{cccc}
\hline Variables & KMO value & Bartlett's value & $\begin{array}{c}\text { Bartlett's } \\
\text { Probability }\end{array}$ \\
\hline PE & 0.822 & 447.652 & 0.000 \\
EE & 0.843 & 607.489 & 0.000 \\
SI & 0.500 & 165.215 & 0.000 \\
PR & 0.881 & 608.435 & 0.000 \\
IM & 0.823 & 396.028 & 0.000 \\
Overall validity & 0.924 & 3022.962 & 0.000 \\
\hline
\end{tabular}

\subsection{Factor Analysis}

This paper uses factor analysis to simplify and generalize 21 items to effectively reduce the variables' dimension. Using factor analysis combined with principal component analysis and variance maxima method, the factor load after maximum variance rotation was performed (see Table 3 ), the total variance explained (see Table 4 ), and the component score covariance matrix (see Table $5)$.

From Table 3, it can be seen that the load factor of the same latent variable on other factors is significantly lower than the load on a certain factor, and the majority of the load values on this factor are greater than 0.7 , indicating that the factor has a better named explanatory. According to the factor 
load distribution, we can know that each item contributes a lot to its respective factor, and it has good convergence and distinctiveness.

In addition, the exploratory factor analysis in this paper shows that the extracted five factors explain $73.087 \%$ of the total variance of the original variables. In general, the original variable has less information loss, and the factor analysis effect is fairly ideal.

Finally, Table 4 shows the covariance matrix of the factors. It can be seen that there is no linear correlation between the five factors, which achieves the goal of factor analysis.

Table 3 Rotated factor loading matrix

\begin{tabular}{cccccc}
\hline \multirow{2}{*}{ Items } & \multicolumn{5}{c}{ Ingredients (factors) } \\
\cline { 2 - 6 } & 1 & 2 & 3 & 4 & 5 \\
\hline PE1 & -0.025 & 0.156 & 0.203 & 0.856 & 0.081 \\
PE2 & 0.152 & 0.168 & 0.090 & 0.853 & -0.007 \\
PE3 & 0.091 & 0.178 & 0.191 & 0.818 & 0.105 \\
PE4 & 0.163 & 0.418 & 0.117 & 0.459 & 0.392 \\
PE5 & 0.195 & 0.352 & 0.165 & 0.421 & 0.361 \\
\hline EE1 & 0.358 & 0.746 & 0.112 & 0.182 & 0.020 \\
EE2 & 0.200 & 0.744 & 0.218 & 0.258 & 0.188 \\
EE3 & 0.280 & 0.714 & 0.192 & 0.136 & 0.249 \\
EE4 & 0.352 & 0.700 & 0.205 & 0.296 & 0.036 \\
EE5 & 0.266 & 0.662 & 0.244 & 0.133 & 0.354 \\
\hline SI1 & 0.340 & 0.229 & 0.262 & 0.165 & 0.743 \\
SI2 & 0.347 & 0.186 & 0.328 & 0.025 & 0.739 \\
\hline PR1 & 0.778 & 0.221 & 0.109 & 0.029 & 0.178 \\
PR2 & 0.772 & 0.232 & 0.287 & 0.123 & 0.184 \\
PR3 & 0.763 & 0.376 & 0.247 & 0.047 & 0.070 \\
PR4 & 0.708 & 0.296 & 0.198 & 0.211 & 0.323 \\
PR5 & 0.689 & 0.276 & 0.274 & 0.117 & 0.271 \\
\hline IM1 & 0.214 & 0.127 & 0.802 & 0.179 & 0.125 \\
IM2 & 0.211 & 0.163 & 0.784 & 0.104 & 0.200 \\
IM3 & 0.191 & 0.215 & 0.763 & 0.136 & 0.284 \\
IM4 & 0.211 & 0.224 & 0.689 & 0.279 & 0.051 \\
\hline
\end{tabular}

Table 4 Composition Score Covariance Matrix

\begin{tabular}{cccccc}
\hline Ingredients & 1 & 2 & 3 & 4 & 5 \\
\hline 1 & 1.000 & 0.000 & 0.000 & 0.000 & 0.000 \\
2 & 0.000 & 1.000 & 0.000 & 0.000 & 0.000 \\
3 & 0.000 & 0.000 & 1.000 & 0.000 & 0.000 \\
4 & 0.000 & 0.000 & 0.000 & 1.000 & 0.000 \\
5 & 0.000 & 0.000 & 0.000 & 0.000 & 1.000 \\
\hline
\end{tabular}

\subsection{Comprehensive Evaluation}

This paper uses the method of calculating the weighted total score of the factors, and evaluates the consumer's purchase intention by the weights, which is the variance contribution rate of the five factors. Finally, the value of each factor can be derived by multiplying its value and its weight. Here, the value of performance expectancy is 0.260 , the value of effort expectancy is 0.336 , the value of social influence is 0.145 , the value of perceived risk is 0.451 , the value of impulsivity is 0.290 . 


\section{Conclusion}

The analysis results show that perceived risk significantly affects consumers' willingness to purchase fresh e-commerce products, and social influence does not significantly affect consumers' willingness to purchase fresh e-commerce products. Efforts expectancy, impulsivity, and performance expectancy have an impact on consumers' purchase intentions. In order to promote the healthy development of China's fresh e-commerce industry, this study proposes the following recommendations:

(1) Reduce consumer perceived risk. First, product quality. Fresh e-commerce companies should strictly control the quality of fresh produce, and match the quality of display with the quality expected by consumers, and even exceed the quality expected by consumers. Second, product pricing. Fresh food E-commerce enterprises should take full account of consumers expected prices to price and the actual situation of enterprises; Third, the quality of service. Fresh e-commerce companies should provide consumers with complete services for the whole process of buying fresh products, so as to increase consumers' goodwill towards enterprises and reduce consumers' perceived risks. Fourth, logistics. Fresh e-commerce companies should build a complete and efficient logistics system or cooperate with responsive third-party logistics companies to reduce the perceived risk of consumers purchasing products and create a good buying experience.

(2) Improve consumers' effort expectancy. First, improve the availability of information. Fresh e-commerce companies should provide detailed, accurate and reliable product information on the Internet, and build a clear, beautiful and simple website platform so that consumers can easily find the information they need. Second, improve the ease of use of the platform. Fresh e-commerce companies should be able to respond to pending orders in a timely manner. At the same time, they should push advertisements and promotions that meet consumer's needs in order to increase the ease of use of the platform and the expectations of consumers.

(3) Reasonable use of consumer impulses. Fresh e-commerce companies can promote consumers by publishing pictures of refined fresh products and photos of foods that can produce strong appetite after being processed. At the same time, they can use holidays to launch promotions and provide quality services and promote consumer willingness to buy impulsively.

(4) Improve consumers' performance expectancy. First, perceived usefulness. Fresh e-commerce companies should provide products that meet the needs of the target market, so that consumers can purchase fresh e-commerce products online to improve the quality of life and efficiency. Second, product characteristics. Fresh e-commerce companies should provide natural, non-polluting, authentic and quality-qualified products according to the needs of consumers, so that consumers are more willing to purchase the product and promote the improvement of consumer performance expectancy.

(5) Promote the impact of social influence on consumers' purchase intention. In the case of companies with more capacity, companies can formulate relevant strategies to promote the positive dissemination of products by opinion leaders and friends around the consumers, and strive to achieve a word-of-mouth effect.

(6) The relevant government departments shall formulate strict quality inspection regulations for fresh produce and publicize the implementation of the regulations so that consumers can purchase fresh products on the Internet with confidence.

(7) Relevant government departments should implement severe penalties for violations of the operations of fresh e-commerce companies, and formulate relevant regulations to regulate the fresh e-commerce market. 


\section{Acknowledgments}

This work was financially supported by the China National University Student Innovation Training Project fund. The project number is 201710626055.

\section{References}

[1] Chinese e-commerce research center. 2017 Chinese Electronic Commerce Market Data Monitoring Report [EB/OL]. Http://b2b.toocle.com/detail--6418193.html, 2017-10-09.

[2] IResearch. 2016 China Fresh E-commerce Industry Research Report [R]. China Electronic Commerce Research Center, 2016, 10-10.

[3] Zhang Xiaheng. Current Situation, Problems and Development Trend about the Logistics of Fresh Product E-commerce [J]. Guizhou Agricultural Sciences, 2014, 42(11):275-278.

[4] Wang Kexi, Dai Anna. On the Influencing Factors of Online Shopping Intentions of Green Fresh Agricultural Products Based on Logit Model [J]. Journal of Hunan University of Science \& Technology (Social Science Edition), 2017, 20(02):87-93.

[5] Yang Xiaopeng, Ai Shizhong. Empirical Research towards the Effect of Website Quality on Purchase Intention-under the Regulatory Role of Asymmetric Information [J]. Information Science, 2015, 33(10):85-90.

[6] Zhou T, Lu Y, Wang B. The Relative Importance of Website Design Quality and Service Quality in Determining Consumers' Online Repurchase Behavior [J]. Dx.Doi.Org, 2009(4):327-337.

[7] Xiao Zhehui. Research on the Shopping Trust of Fresh Produce under E-commerce Environment [D]. Wuhan: Huazhong University of Science and Technology, 2015:1-128.

[8] Sun Yi. Research on Consumer Willingness to Purchase Fresh Produce Based on E-commerce Platform [J]. Marketing Management Review, 2017(01):151.

[9] Chen Fanjiao. Empirical Research towards the Effect of Consumers' Satisfaction to Purchase Fresh Products Online [J]. Journal of Commercial Economics, 2016(08):49-51.

[10] Dan Bin, Zheng Kaiwei, Shao Bingjia. Research on the Pre-sale Model of "Internet + " Fresh Produce Supply Chain Based on Consumer Crowdfunding [J]. Rural Economy, 2017(02):83-88.

[11] Li Yimei. Research on the Influence of Features of E-Commerce of Fresh Product On Customer's Perceived Risk and Purchase Intention [D]. South China University of Technology, 2016.

[12] ZhangYingyu, Zhang Mengjia, Wang Qiang et al. The Research on Purchasing Intention of Fresh Agricultural Products under O2O Mode Based on the Framework of Perceived Benefits-Perceived Risk [J]. China Soft Science, 2015(06):128-138.

[13] Chunhua XIE. The Influence of Perceived Risk on Purchase Intention - A Case study of Taobao Online Shopping of Fresh Fruit [J]. Asian Agricultural Research, 2017, 9(05):30-35.

[14] Zhu Junhong, Zhu Liwei, Huang Xinfei. Empirical Study on Influencing Factors of Online Purchase Intention for Fresh Agricultural Products Based on Structural Equation Modeling [J]. Journal of Shanghai Business School, 2017, 18(03):50-58.

[15] Chaudhuri. A Product Class Effects on Perceived Risk: the Role of Emotion [J]. International Journal of Research Information Marketing, 1998(15):157-168.

[16] Zhao Baoguo, Cheng Yinghui. Research on Influencing Factors of Consumers' $\square$ Purchase Intention on Online Group Buying [J]. Journal of Central University of Finance \& Economics, 2013(10):91-96.

[17] Yan An. Study on Impacting Factors of Baidu Products Usage Based on UTAUT [J]. Journal of Modern Information, 2012, 32 (11): 100-104 + 122.

[18] Venkatesh V., Morris MG, Davis GB, Davis FD. User Acceptance of Information Technology: toward A Unified View [J]. MIS Quarterly, 2003, 27(3):425-478.

[19] Cheng Xiaolu. The Study of Consumers' Acceptance Model Based on UTAUT [D]. Zhejiang University, 2011. 